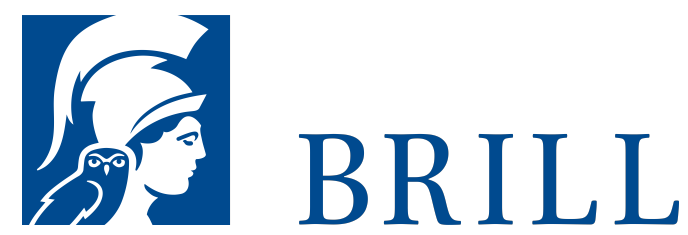

\title{
Braucht Theologie Philosophie?
}

Von Bultmann und Heidegger bis Voegelin und Assmann

Author: Otto PÃ $₫$ ggeler

Die Nordrhein-WestfÃ $\not$ lische Akademie der Wissenschaften und der KÃ̃¹/4nste ist eine Vereinigung der fã $1 / 4$ hrenden Forscherinnen und Forscher des Landes. Sie wurde 1970 als Nachfolgeeinrichtung der Arbeitsgemeinschaft fã $1 / 4 \mathrm{r}$ Forschung des Landes Nordrhein-Westfalen gegrã $1 / 4$ ndet. Die Akademie ist in drei wissenschaftliche Klassen f̊̃ $1 / 4$ r Geisteswissenschaften, f $\tilde{\mathrm{A}} 1 / 4 \mathrm{r}$ Naturwissenschaften und Medizin sowie fã $1 / 4 \mathrm{r}$ Ingenieurund Wirtschaftswissenschaften und in eine Klasse der KÃ $1 / 4$ nste gegliedert.

Mit Publikationen zu den wissenschaftlichen VortrÃagen in den Klassensitzungen, zu Ã ffentlichen Veranstaltungen und Symposien will die Akademie die Fach- und allgemeine Ãffentlichkeit Ã $1 / 4$ ber die Arbeiten der Akademie und ihrer Forschungsstellen informieren.

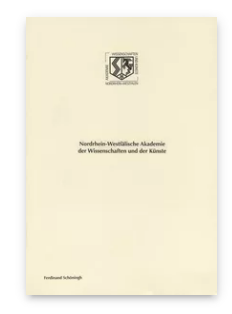

Pages: 32 Seiten

Language:

German

Subjects:

General,

Philosophy

Publisher: Brill |

SchÃ $\llbracket$ ningh

Series:

Nordrhein-

WestfÃalische

Akademie der

Wissenschaften und

der KÃ $1 / 4 n s t e$ -

VortrÃoge:

Geisteswissenschaften,

Volume: 410

E-Book (PDF)

Released online:

3o Dec 2019

ISBN: 978-3-

657-76372-6

List price

USD ÂA \$28.00

Paperback

Publication date:

23 Jan 2007

ISBN: 978-3-

5o6-76372-3

List price

USD Â \$28.00 
For more information see brill.com

Order information: Order online at brill.com +44330 333 0049 | customerservices@brill.com Submission information: brill.com/authors

Titles published by Brill | Fink, Brill | mentis or Brill | Schöningh: +49(o)715413279216| brill@brocom.de 